\title{
Outside the Safe Operating Space of the Planetary Boundary for Novel Entities
}

\section{Persson, Linn; Carney Almroth, Bethanie M.; Collins, Christopher D.; Cornell, Sarah; de Wit, Cynthia A.; Diamond, Miriam L.; Fantke, Peter; Hassellöv, Martin; MacLeod, Matthew; Ryberg, Morten W.}

Total number of authors:

14

Published in:

Environmental Science and Technology

Link to article, DOI:

10.1021/acs.est.1c04158

Publication date:

2022

Document Version

Publisher's PDF, also known as Version of record

Link back to DTU Orbit

Citation (APA):

Persson, L., Carney Almroth, B. M., Collins, C. D., Cornell, S., de Wit, C. A., Diamond, M. L., Fantke, P., Hassellöv, M., MacLeod, M., Ryberg, M. W., Søgaard Jørgensen, P., Villarrubia-Gómez, P., Wang, Z., \& Hauschild, M. Z. (2022). Outside the Safe Operating Space of the Planetary Boundary for Novel Entities. Environmental Science and Technology, 56(3), 1510-1521. https://doi.org/10.1021/acs.est.1c04158

\section{General rights}

Copyright and moral rights for the publications made accessible in the public portal are retained by the authors and/or other copyright owners and it is a condition of accessing publications that users recognise and abide by the legal requirements associated with these rights.

- Users may download and print one copy of any publication from the public portal for the purpose of private study or research.

- You may not further distribute the material or use it for any profit-making activity or commercial gain

- You may freely distribute the URL identifying the publication in the public portal 


\section{Outside the Safe Operating Space of the Planetary Boundary for Novel Entities}

Linn Persson,* Bethanie M. Carney Almroth, Christopher D. Collins, Sarah Cornell, Cynthia A. de Wit,* Miriam L. Diamond, Peter Fantke, Martin Hassellöv, Matthew MacLeod, Morten W. Ryberg, Peter Søgaard Jørgensen, Patricia Villarrubia-Gómez, Zhanyun Wang, and Michael Zwicky Hauschild

Cite This: Environ. Sci. Technol. 2022, 56, 1510-1521

ABSTRACT: We submit that the safe operating space of the planetary boundary of novel entities is exceeded since annual production and releases are increasing at a pace that outstrips the global capacity for assessment and monitoring. The novel entities boundary in the planetary boundaries framework refers to entities that are novel in a geological sense and that could have large-scale impacts that threaten the integrity of Earth system processes. We review the scientific literature relevant to quantifying the boundary for novel entities and highlight plastic pollution as a particular aspect of high concern. An impact pathway from production of novel entities to impacts on Earth system processes is presented. We define and apply three criteria for assessment of the suitability

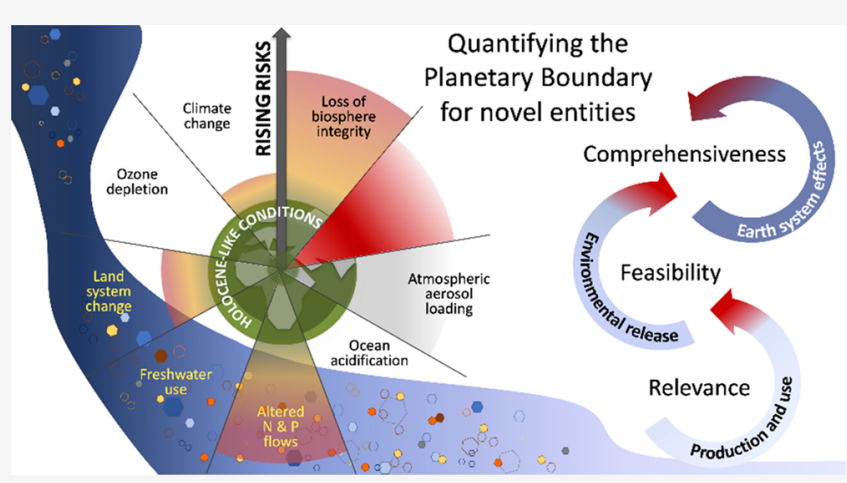
of control variables for the boundary: feasibility, relevance, and comprehensiveness. We propose several complementary control variables to capture the complexity of this boundary, while acknowledging major data limitations. We conclude that humanity is currently operating outside the planetary boundary based on the weight-of-evidence for several of these control variables. The increasing rate of production and releases of larger volumes and higher numbers of novel entities with diverse risk potentials exceed societies' ability to conduct safety related assessments and monitoring. We recommend taking urgent action to reduce the harm associated with exceeding the boundary by reducing the production and releases of novel entities, noting that even so, the persistence of many novel entities and/or their associated effects will continue to pose a threat.

KEYWORDS: chemical pollution, plastic pollution, unknown planetary boundary threats, Earth system impacts, cap on emissions, chemicals management capacity

\section{INTRODUCTION}

Chemical pollution has the potential to cause severe ecosystem and human health problems at different scales, ${ }^{1}$ but also to alter vital Earth system processes on which human life depends. "Chemical pollution" was included as one of nine planetary boundaries, ${ }^{2}$ in response to this understanding. Steffen et al. ${ }^{3}$ renamed the "chemical pollution" boundary to "novel entities" (NE), defined as "new substances, new forms of existing substances and modified life forms", including "chemicals and other new types of engineered materials or organisms not previously known to the Earth system as well as naturally occurring elements (for example, heavy metals) mobilized by anthropogenic activities". Steffen et al. ${ }^{3}$ argued that the anthropogenic introduction of novel entities to the environment is of concern at the global level when these entities exhibit persistence, mobility across scales with consequent widespread distribution and accumulation in organisms and the environment, and potential negative impacts on vital Earth System processes or subsystems.
So far, no quantitative boundary has been defined for the novel entities boundary, although, some specific chemicals are quantified under other planetary boundaries, such as greenhouse gases and CFCs. Conditions where chemicals may pose a planetary threat have been specified, ${ }^{4,5}$ and ways in which cascading systemic effects come to represent a planetary-scale problem have been explored, for example, for plastics ${ }^{6}$ (mixtures of nonpolymeric and polymeric chemicals). The high costs to society associated with current use and environmental releases of novel entities ${ }^{1,7-11}$ offer a strong additional arguments for pursuing prompt action addressing

Received: June 23, 2021

Revised: November 26, 2021

Accepted: November 30, 2021

Published: January 18, 2022

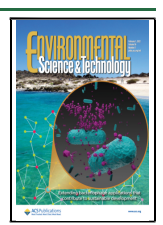


this complex planetary boundary. An investigation and assessment of the boundary can draw attention to global risks to humans and biota, and drive actions to mitigate them. As part of the planetary boundaries framework, a quantified boundary can also offer scientific underpinning (e.g., targets and indicators for developing action and effectiveness evaluation) in policy processes, such as the UN Strategic Approach to International Chemicals Management and its successor. $^{12}$

This paper reviews the evolution of the scientific discussion related to the planetary boundary for novel entities (NE-PB) since 2009 and discusses options for its quantification. We focus on chemical pollution, highlighting plastic pollution as a particular subset issue of high concern, and provide an assessment of the current status of this planetary boundary. Chemicals at large, including plastics, have been identified as fulfilling the characteristics of a novel entity. ${ }^{13,14}$ While both are similar in many regards, the differences between plastics and other chemicals provide opportunities for us to explore a wide range of impacts in defining new control variables for this planetary boundary. We conclude that increasing trends of production and emissions of diverse novel entities that outstrip our efforts at safety assessment and monitoring are a transgression of the planetary boundary and that immediate actions are needed to return us to the safe operating space.

For the analysis, we follow the definition of NEs suggested by Steffen et al. ${ }^{3}$ Novel means new in the geological sense, that is, created, introduced, or recirculated by humans. The entities are intentionally and unintentionally manufactured chemicals, engineered materials, and their transformation products, that have the potential to cause effects on vital Earth system processes $^{15}$ as well as naturally occurring elements and materials mobilized in new ways, new forms, or at substantially higher rates by anthropogenic activities. By Earth system processes we mean the biophysical processes that together determine the self-regulating capacity of the planet, ${ }^{2}$ that is, the interacting physical, chemical, and biological processes on land, in the oceans, and in the atmosphere. This macro perspective ensures the NE-PB is conceptually aligned with the other planetary boundaries, and provides a necessary complement to the existing subglobal societal concerns framing ecological and human health as the direct end points of chemical pollution.

\section{THE PLANETARY BOUNDARY FOR NOVEL ENTITIES}

Several studies have addressed the topic of a planetary boundary for chemical pollution and novel entities. One line of discussion has focused on what kinds of chemical substances should be considered, in terms of their systemic behavior. Sala and Saouter ${ }^{16}$ proposed that synthetic chemicals that degrade slowly and accumulate in the environment should be prioritized. Diamond et al. ${ }^{4}$ argued that chemical pollution, in aggregate, poses a threat to the integrity of the global ecosystem and cautioned against delaying action to reduce pollution pressure while attempting to increase scientific certainty. As a first step, they recommended considering well-known chemicals such as persistent organic pollutants (POPs) and persistent, bioaccumulative and toxic (PBT) chemicals. Bernhardt et al. showed that the high rate of change in production and variety of synthetic chemicals over the last four decades outpaces many other drivers of change. ${ }^{17}$ Perlinger et al. ${ }^{18}$ proposed that "measurement and modeling of the fate and transport of harmful compounds that disseminate globally through repeated cycles of atmospheresurface exchange should be incorporated into efforts to identify safe boundaries and integrate those boundaries into systems of governance".

Among novel entities, plastic pollution has been elevated to a potential NE-PB issue of high concern. ${ }^{6,14,19}$ After several decades of mass production, plastics are now ubiquitous across the planet. $^{20,21}$ The whole production cycle of plastics carries climate impacts, ${ }^{22-24}$ and plastics may also affect biodiversity through physical impacts, for example, via entanglement or ingestion, ${ }^{25}$ adding to other large pressures on biodiversity. ${ }^{26}$ The understanding of what is harmful or hazardous from a planetary perspective has thus expanded to include effects beyond toxicity as the current major focus of chemicals management.

Another line of discussion focuses on downstream effects. For example, chemical footprint evaluation aims to assess the carrying capacity of receiving ecosystems to define the NE-PB in terms of total chemical inputs that can be absorbed without unacceptable negative impacts. ${ }^{16,27-29}$ Even without boundary quantification, the concept of planetary boundary threats has been used to define chemical profiles for screening chemicals for unwanted environmental exposure profiles. ${ }^{30}$

A particularly challenging aspect for NE-PB quantification is the potential for known and unknown novel entities to cause so far unknown effects. ${ }^{5,13}$ Environmental monitoring is targeted on known novel entities resulting in limited scanning for "unknown unknowns". 31

\section{AN IMPACT PATHWAY AND CRITERIA FOR A CONTROL VARIABLE}

The scientific rationale behind the planetary boundary concept is that Earth's climate stability and ecosystem resilience, seen throughout $\sim 10000$ years of the Holocene, are the result of dynamic biophysical interactions that can now be radically altered by human activities. The further human activities push Earth away from Holocene-like conditions, the higher the risks of large-scale and irreversible change, because thresholds in Earth system processes are intrinsic features of the Earth system. $^{32,33}$ The planetary boundaries framework identifies "control variables", such as $\mathrm{CO}_{2}$ concentration, nitrogen fixation rate, and seawater aragonite saturation, that track both Earth system behavior (i.e., Earth's temperature, nutrient limitation, and ocean carbon sinks, respectively) and the perturbation that may provoke crossing of thresholds, which are linked to one or several control variables. A control variable is defined as a measurable parameter that is causally related to a specific boundary. The positions of the planetary boundaries are set at the lower end of the scientific uncertainty zone of "safe" Holocene-like conditions. ${ }^{2}$

For novel entities introduced exclusively by humans (e.g., xenobiotic organic chemicals, plastics), by definition there is no "natural variability" against which a control variable can track change on human time scales, nor is there a biophysical precedent for identifying thresholds. Another complication is that the NE-PB has a wide range of possible end points (including affecting other $\mathrm{PB}$ processes). Different categories of NE impacts can be distinguished: ${ }^{4}$ direct biological effects, such as decline in top predators following widespread DDT use, with subsequent cascading ecological effects; physical pathways such as albedo reduction from black carbon particles affecting climate; and chemical reactions that cannot be 




Figure 1. A generalized impact pathway for novel entities connecting production capacity, environmental release, fate, and distribution to perturbation of Earth system processes.

controlled postrelease, like the breakdown of ozone by CFCs on polar stratospheric clouds.

Defining control variable(s) is key to operationalizing a planetary boundary and assessing the Earth system's position with respect to thresholds or tipping points. Control variables for the NE-PB must be based on a scientific understanding of the causal mechanisms that link NE introduction to disturbance of Earth system effects as presented in the impact pathway in Figure 1. Complex and diverse impact mechanisms mean that no single control variable can capture the full scope of the safe operating space for NEs and quantification in terms of trends (pressures) rather than system conditions may be more appropriate for taking a precautionary approach.

The impact pathway approach opens a very large set of possibilities, so we define the following criteria to inform the selection of control variable options:

Feasibility (F): Can it be measured? Data availability must permit quantification at relevant spatial and temporal scales and comparison with other biophysical monitoring data.

Relevance (R): Can it be robustly linked to effects? It must be possible to link the control variable consistently to one or more effects that are known to influence Earth system functioning, i.e. establish a cause-effect link.

Comprehensiveness (C): Does it capture the planetary scale of the problem? The control variable must indicate the totality of the potential impacts of novel entities, through cause-effect thresholds affecting a given Earth system process or through effects on one or more of the other PBs.

The ease of quantification (feasibility) is generally highest early in the impact pathway (to the left in Figure 1). For a control variable defined according to exposure or disturbance (to the right in Figure 1), there is robust knowledge of effects (relevance) for a limited number of novel entities but uncertainty rises because assumptions and parametrizations have to be made to quantify each step along the pathway. Comprehensiveness is higher earlier in the impact pathway, as the number of possible fates and effects increases from left to right, while the ability for current policies and actions to exert control over the impacts decreases from left to right along the pathway.

\section{CONTROL VARIABLES FOR THE PLANETARY BOUNDARY OF NOVEL ENTITIES}

Below we evaluate options for control variables guided by our criteria, proceeding from left to right along the NE-PB impact pathway (Figure 1).

Production of Novel Entities. Production of novel entities is rapidly increasing. The chemical industry is the second largest manufacturing industry globally. ${ }^{1}$ Global production increased 50-fold since 1950, and is projected to triple again by 2050 compared to $2010 .^{34}$ Material extraction as feed stocks for novel entities was approximately 92 billion tonnes globally in 2017, and is projected to reach 190 billion tonnes by 2060. ${ }^{1}$ There are an estimated 350000 chemicals (or mixtures of chemicals) on the global market. ${ }^{35}$ Nearly 70000 have been registered in the past decade; many chemicals (nearly 30000 ) have only been registered in emerging economies, where chemical production has increased rapidly, but chemicals management and disposal capacity often are limited. The production of intended chemicals entails the unintended production of byproducts, transformation products, and impurities which may not be considered under chemicals assessments and management measures.

Here, we consider the control variables trend in production volumes of chemicals, trend in production volumes of plastics, and the share of chemicals on the market that are assessed for risk or safety (Table 1).

The trend in production volume of chemicals approximates the aggregate chemical burden on the Earth system. This metric could be a feasible control variable because production data are known by producers and are often reported to regulators for a large number of chemicals. ${ }^{1,36}$ However, full data are often not publicly available, prompting calls for the release of such data from producers, trade organizations, and governments. ${ }^{36}$ Chemicals could be binned according to production facility, feedstocks, or parent compounds, or by specific categories such as structural traits or uses, since it is likely to be most feasible to obtain highly aggregated data. Figure 2 shows the trend in global production capacity for a number of groups of novel entities, all showing high growth rates over the last couple of decades. These were chosen as representative chemicals where respective production/production capacity data were publicly 


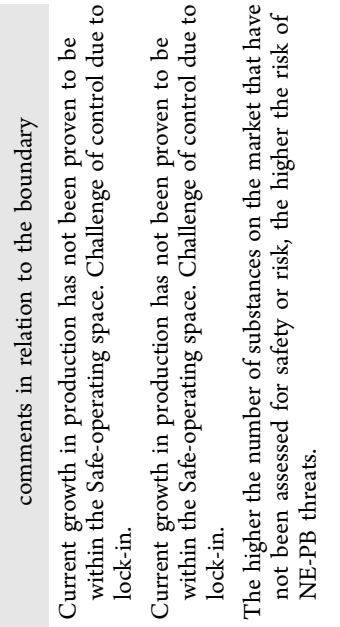

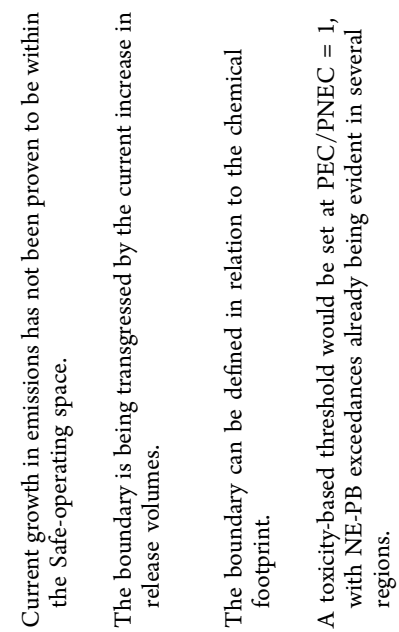
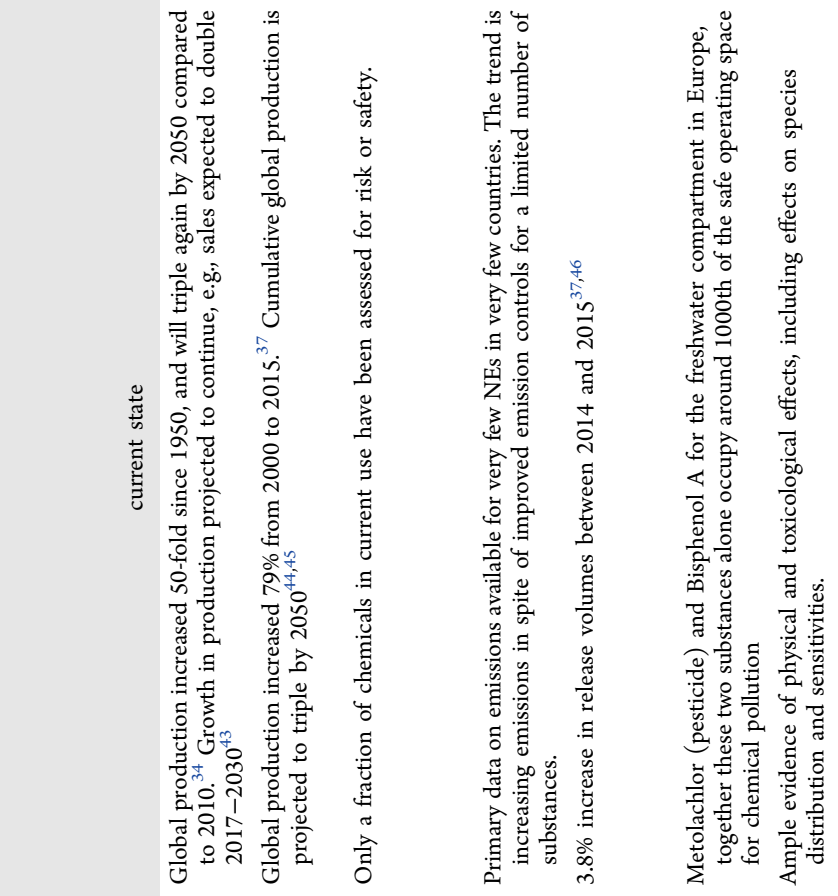

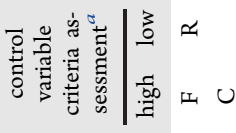
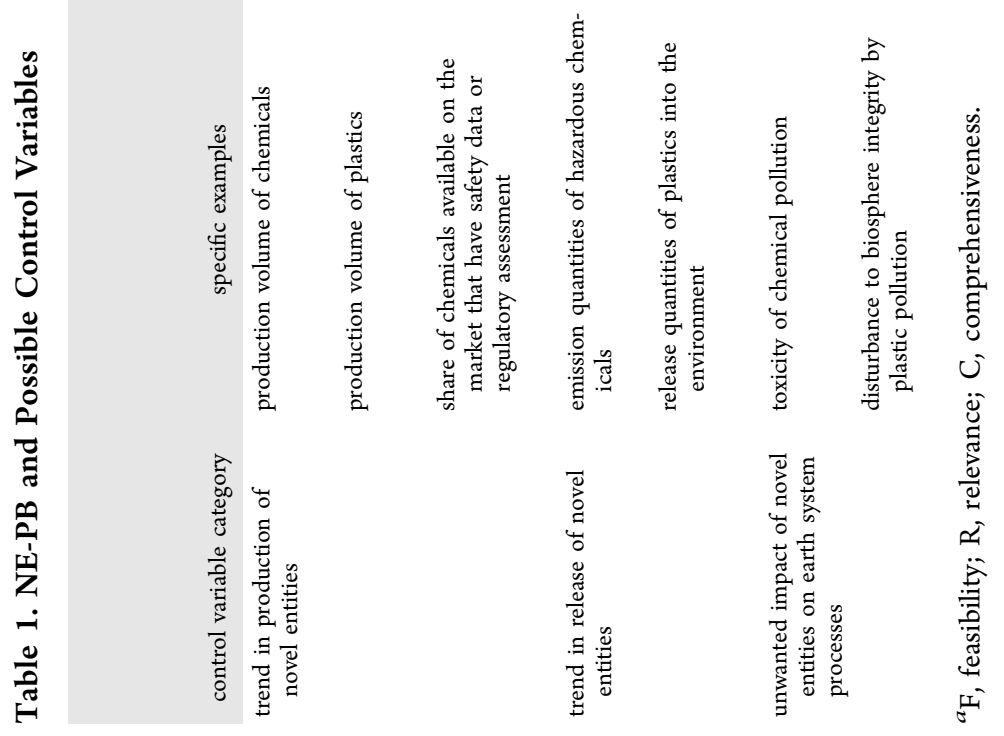




Figure 2. Current rising global trends of chemical industry production, expressed as the relative growth in some novel entities between 2000 and 2017 (for when comparable data are available): 1 . Global production capacity for the chemical industry as a whole, plastics production and pesticide active ingredients (for which earliest data are from 2008); 2. Per capita production capacity in weight for key monomers and solvents: benzene, butadiene, ethylene, propylene, toluene, and xylene, 3: Global consumption of antibiotics. Data from the Global Chemicals Outlook II, ${ }^{1}$ Geyer et al. 2017, ${ }^{37}$ and Søgaard Jørgensen et al. ${ }^{38}$

available. Data are normalized due to different unit scales used when reporting. Individual graphs for each novel entity are given in the Supporting Information (SI).

The trend in total chemical production captures potential planetary impacts at a high level of aggregation, making it comprehensive. A compelling reason to consider total chemical production as a control variable is that it exposes the vexing supply side issue of the "lock-in" effect, where economic, technical, political, and bureaucratic inertia maintain production despite imperatives for reduction. ${ }^{39,40}$ Maintenance of production can cause a shift between chemicals with different types of functionality. For example, in the U.S., $77 \%$ of bromine was used to produce leaded gasoline in the 1960s. With the phase-out of leaded gasoline, bromine was used increasingly to produce brominated flame retardants, which then became the major use. ${ }^{41}$ Similarly, silver production has shifted from declining use in analogue photoimaging to increased use as a biocide. Further, most production capacity is for multiple related chemicals and not a single entity. The lock-in effect means that a restriction in production and use of one set of chemicals leads to a shift in production of closely related chemicals (e.g., dielectric fluids shifting from PCBs to chlorinated paraffins, polycarbonate production shifting from bisphenol $\mathrm{A}$ to other bisphenols), and not to a reduction in total chemical production. Since chemicals differ widely in their effect potency, shifting production from one chemical to another can increase or decrease related effects on the Earth system or lead to other types of effects (burden shifting).

The trend in total chemical production as a control variable may, at first glance, seem to have low relevance because links between chemical production and effect variables are not obvious and can be tenuous and difficult to assess: knowledge is lacking of the potential for adverse effects caused by the high number of chemicals, with limited data on chemical mixtures as found in the environment, produced intentionally and unintentionally. ${ }^{42}$ Production volume can be argued to be directly linked to the immediate release of some chemicals (e.g., pesticides that are intentionally applied; down-the-drain chemicals in personal care products), but eventual release is more difficult to quantify (e.g., CFCs used as blowing agents in polystyrene insulation are released upon building renovation; dyes and other plastic additives are released as plastics age). Another aspect is that chemical production can account for inevitable global release since production is fed into highly complex, and poorly known global supply chains. A precautionary assumption of inevitable environmental release, however, increases the relevance of the trend in chemical production as a control variable.

Trend in the production volume of plastics could be used as a control variable. Worldwide use of plastics has increased steadily since the 1950 s, with global production increasing by $79 \%$ from 2000 to $2015 .{ }^{37}$ Cumulative global production is projected to triple by 2050 to reach 33 billion tonnes. ${ }^{44,45}$ The production of plastic, and consequently, plastic waste, is predicted to grow beyond the efficacy of the mitigating strategies to fight plastic pollution globally. ${ }^{47}$ Plastic production data are globally available, enabling continuous monitoring of production volumes, see Figure 2 for the recent decade of increase. Thus, this is a feasible control variable.

Plastic production is strongly associated with lock-in effects with raw materials, particularly fossil fuels. Four percent of fossil fuel is used for production of plastics materials, ${ }^{48}$ and nearly $99 \%$ of feedstock for plastic materials come from fossil fuels. ${ }^{49}$ Plastics are just one component in a complex industrial web that also uses fossi-fuel-based feedstocks to produce industrial fertilizers, solvents, and other chemicals. ${ }^{36}$ Plastics are thus linked with the two core planetary boundaries of climate change and biosphere integrity, ${ }^{3}$ making plastic production volume a strong proxy for human-caused changes and a comprehensive control variable. However, it is located far to the left on the impact pathway and does not account for environmental interactions and effects. Sustainable consumption patterns, reuse or recycling and the catching of mismanaged plastic waste can contribute to decoupling the amount of plastic produced from its potential planetary impacts. ${ }^{50}$ Production volume, therefore, has low relevance as an indicator for disturbance of Holocene stability. However, whether these control measures, at a global scale, can occur at a rate commensurate with increasing production is highly debatable. $^{7,47}$

The share of chemicals with safety data or regulatory assessments is an option for the NE-PB control variable. Many countries have legislation and systems for assessment of hazard or risk for novel chemical substances, albeit with high variability in assessment requirements and capabilities between countries. Chemicals with safety data are those for which information on hazardous properties have been made available to regulators, users or the public. Chemicals with regulatory assessments refer to those whose hazardous properties or risks have been additionally assessed by regulators.

The relevance of this control variable for the NE-PB is higher than production volumes because effects are better known, and possibly controlled. Many assessment components (i.e., toxicity, persistence, and long-range transport potential) have a direct bearing on Earth system effects. ${ }^{13,51}$ Nevertheless, the relevance is constrained by the fact that no safety data requirement or regulatory assessment scheme can include all 
possible impacts of chemicals on Earth system processes. ${ }^{52}$ Its relevance as an operational control variable depends on the quality of the safety data or regulatory assessments available. ${ }^{53}$

The feasibility of this control variable is limited. Many large chemical producers and users are not covered by effective chemicals management or occupational exposure legislation and/or chemical inventories. ${ }^{35,52,54}$ In addition, frameworks governing chemicals on the market show high variability across jurisdictions, including the scope of regulatory assessments, ranging from compliance check (e.g., whether all required data fields are filled in), to plausibility check of reported safety data, to in-depth hazard and risk assessments of a chemical by combining reported and literature safety data.

Using the EU REACH (Registration, Evaluation, Authorisation and Restriction of Chemicals) as an example, as of December 2020, 23000 chemical substances were registered. ${ }^{55}$ Among them, over 12000 substances were registered as nonintermediates (intermediates have reduced safety data requirements) above 1 tonne per year production, of which about 2400 substances have been, or are being, assessed and addressed (403 with ongoing regulatory risk management, 786 with currently no further actions proposed, and 1181 with regulatory risk management under consideration). Thus, even in this small subset of the chemical universe, around 10000 substances $(80 \%)$ are yet to be assessed after over 10 years of the operation of REACH. A control variable based on safety data or regulatory assessments does not easily lend itself to the establishment of a comprehensive quantitative boundary because it does not translate to an analysis of the overall impacts of unsafe chemicals.

A key aspect of the safety assessments of chemicals and of other NEs is the handling of the unknown NE-PB threats. The risks associated with the release of new entities from the technosphere to different environmental compartments are linked to possible effects over the full range of planetary boundaries. For example, novel entities could surprise us, for example, with effects on ocean chemistry affecting sea spray formation, ${ }^{56,57}$ an important component of the climate system, ${ }^{58}$ or with effects of antibiotic-resistant bacteria with global spread. ${ }^{59}$ A NE-PB addition to risk and hazard assessments could capture chemicals that would not be highlighted in current assessment schemes. The planetary boundary threat screening approach suggested by MacLeod et al. ${ }^{13}$ has already been tested on a set of currently unregulated chemicals found in the Arctic environment, ${ }^{30}$ showing that some chemicals of emerging concern did not fit the wellestablished profiles for persistent organic pollutants (POPs) or very persistent/very accumulative chemicals, but scored high on the profiles of potential planetary boundary threats.

Trend in Release of Novel Entities. Moving further to the right in the impact pathway, the trends of emission or release of NEs to the environment could be a control variable. Millions of tonnes of NEs are released to the environment every year, including air emissions, water discharges, and solid and hazardous waste releases, ${ }^{1}$ along entire supply chains of products and services. NEs are increasingly found in the most remote locations of the planet, for example, organophosphate esters in the Arctic Ocean, ${ }^{60}$ and microplastic particles in the deep ocean ${ }^{61}$ and high mountains. ${ }^{62}$ Different groups of NEs can be targeted for this control variable. Here, we discuss two options, emissions of hazardous chemicals and release of plastic to the environment.
Trend in emission quantities of hazardous chemicals scores high on the relevance criterion, since it captures the magnitude of the flow to the environment of chemicals that are potential NE-PB threats. Despite improvements of emissions and waste management in many jurisdictions, emissions of chemicals are projected to continue to increase with consequent effects on ecosystems and human health; reduction targets to 2030 are, for instance, projected not to be met for the European Union with the current trends and developments. ${ }^{63}$

The feasibility of this control variable hinges on the definition of hazardous, as well as the data availability on emissions of hazardous substances at a global scale across the life cycle of the chemical. One possible data source is the national and regional Pollutant Release and Transfer Registers (PRTR). ${ }^{64}$ However, many countries lack these types of registers, the number of chemicals reported is limited, emission reports are often incomplete and uncertain, ${ }^{65}$ and not all types of emissions are considered (e.g., mainly large point source emissions over certain volumes are captured ${ }^{66}$ ). Creating an emissions-based control variable with global coverage for just a small fraction of total chemicals would require numerous assumptions and would rely on extrapolation of data. Extrapolation is questionable when moving from countries with release inventories, to countries that lack them. ${ }^{67}$ Nevertheless, if data are available, this approach allows for differentiating certain chemicals and chemical uses with high release potential.

The comprehensiveness of this control variable is limited because the hazards are defined in limited scope in terms of ecosystem and human health, not in terms of potential biophysical thresholds and interactions with other PBs. The high aggregation of reported data also decreases the operational usefulness as different substances (e.g., arsine gas, different organic and inorganic arsenic compounds) within the same reported substance group (e.g., "arsenic and compounds") will differ widely in their environmental fate and behavior. The knowledge of toxicological properties is also limited to a small subsection of chemicals. ${ }^{42}$ In spite of its shortcomings, this control variable carries the strength of representing realistic exposure, albeit for a limited number of chemicals and not necessarily over a chemical's life cycle.

For the trend in release quantities of plastics into the environment, Villarrubia-Gómez et al. ${ }^{6}$ identified various pathways and mechanisms through which plastic pollution can influence biophysical thresholds and change Earth system processes, suggesting that this control variable has high potential relevance. Numerous studies have sought to quantify the global environmental release of plastics. ${ }^{7,46,47,68}$ These data provide insights on release hotspots, but highlight data constraints that reduce the feasibility of this control variable. For example, countries with a less developed industrial base lack resources for monitoring plastic losses. Also, different forms of plastic have different release routes. Ryberg et al. ${ }^{46}$ estimated that about $2.4 \%$ of plastics produced globally are lost to the environment, of which two-thirds are macroplastic ( $>5$ $\mathrm{mm})$ and a third is microplastic ( $\sim 1 \mathrm{~nm}$ to $5 \mathrm{~mm}$ in size). Most macroplastics are lost because of littering and poor waste management. ${ }^{46}$ Some microplastics are lost to the environment in their manufactured form, such as nurdles, flakes, powder and microbeads. ${ }^{69-71}$ This makes quantitative estimates uncertain and presents challenges for monitoring and assessment of effects. Methods are currently lacking for linking the steps in the impact pathway from releases of plastic to disturbance of 
the Earth system, ${ }^{46,72}$ limiting the comprehensiveness of the release of plastics as a control variable.

Unwanted Impact of Novel Entities on Earth System

Processes. Choosing a control variable further to the right in the impact pathway would mean looking at exposure and effects in terms of disturbance of Earth system processes, which increases its relevance. Feasibility would require narrowing the scope of the control variable to particular data-rich chemicals and certain end points or specific subsystems of the Earth, thus also reducing comprehensiveness. The planetary boundary for this control variable would represent a "safe" level of chemical pollution. The goal is to protect biosphere integrity for a given environmental compartment (e.g., freshwater ecosystems) from the effects of the chemicals included in the assessment.

In principle, the control variable can be defined for a given spatial scale, based on the compartment volume and its renewal rate. All chemical releases have the potential to occupy shares of the safe operating space within this boundary, in accordance with their release rates and their environmental persistence and toxicity potential. However, feasibility is constrained by the need to account for the large number of chemicals produced and released (with the data limitations discussed above), and estimating related effects is a challenge. For agricultural chemicals, quantitative estimates of the impacts may be derived from combining crop-specific field application data (e.g., from product labels) with crop production area statistics (e.g., FAOSTAT) as a proxy for treated area, emissions per unit mass applied and impacts per unit mass emitted into a given compartment (which could be estimated using mass balance models). For industrial chemicals, quantitative estimates of the impacts may be derived across the chemical's life cycle from combining chemical production data and data on uses, emissions, environmental fate and transport (including persistence), and disposal. In other words, this requires information that is also needed for control variables early in the impact pathway, and additional information on ecological exposure and potency with respect to relevant Earth system effects.

Since this control variable is close to the effect level of Earth system processes, robust boundary-setting is possible (and is the basis of critical loads approaches already in use), but it is not very comprehensive as compartment-based assessment may miss larger-scale dynamics. Reliable information for the various relevant aspects that describe more or less the entire impact pathway along the chemical's life cycle is not available for most chemicals. However, the total cumulative chemical pressure on biosphere integrity is likely to be dominated by a limited number of chemicals (reflecting the quantities produced, used and released to the environment in combination with the inherent characteristics of the chemicals like persistence, mobility and toxicity). Posthuma and colleagues investigated the toxicity pressure from more than 12000 chemicals in over 22000 European water bodies and found that 15 compounds explained nearly $99.5 \%$ of the cumulative ecotoxicity pressure. $^{73}$ Walters et al. modeled the biomagnification potential of organic chemicals, thus contributing with another tool for screening. ${ }^{74}$ While such studies are based on modeling with several limitations such as the interaction of novel entities, the approach could help to prioritize substance classes, regional patterns, or effect trends. To make the monitoring of the planetary boundary operational, chemicals that dominate cumulative impacts could be used as "indicator" chemicals. These would be identified in a prescreening process, combining estimates for production volume or capacity (e.g., market statistics) with environmental persistence (e.g., using the inverse of degradation half-life estimates as proxy) and impact potency (e.g., chronic ecotoxicity test data). To consider the transformation of various chemicals into persistent transformation products, total production data could be combined with metabolism rates for chemicals that contribute to the formation of such persistent "indicator" chemicals. And finally, the ratio of the cumulative chemical impact and the available space within the boundary for a given biosphere compartment could define whether the boundary is transgressed and to what extent, while allowing the main contributing chemicals to be identified.

Several assumptions made in defining the boundary must be considered. First, there is an assumption about homogeneous mixing and exposure within the compartment over the considered time frame. This assumption is fair for air and perhaps for water, but less applicable to more complex compartments like soil and sediment, resulting in underestimation of exposures. Second, the aggregation of the occupation of operating space across chemicals assumes additivity without correcting for possible mixture effects, giving at most 1 order of magnitude uncertainty, ${ }^{75}$ in addition to at least another order of magnitude uncertainty related to intra- and interspecies differences for deriving effect estimates. $^{76}$ Other assumptions in deriving the cumulative impact are linked to nonspatialized emission and impact estimates ignoring spatial differences (e.g., in water chemistry, species richness, species vulnerability, degradation rates), and to estimation methods applied to cover data gaps in use/ release patterns and persistence, yielding potentially 2-3 orders of magnitude uncertainty. ${ }^{7}$

Another effect-focused control variable could consider plastics' disturbances to biosphere integrity, through physical and toxic effects of plastics and resulting changes in species distribution. While the perception of impacts of marine debris is larger than the accumulated evidence of ecological impacts, ${ }^{78}$ reviews and meta-analyses of published experimental data show that microplastics do have negative effects in numerous species. ${ }^{79-81}$ Impacts of microplastics on individual organisms and communities have been studied using numerous laboratory models, providing understanding of mechanisms of toxicity in marine organisms ranging from zooplankton to large vertebrates. ${ }^{79,82}$ Although there are still mismatches between the concentrations and types of microplastics documented in the environment and those used in laboratory effect studies, ${ }^{83}$ meta-analyses allow for some generalized understanding of the toxicity of microplastic particles. Newly developed mathematical models account for the large diversity in microplastic particles themselves, by applying extrapolation factors to account for underestimation in concentrations, and including species sensitivity distribution based on ecotoxicity data, allowing for more robust comparison of data sets. ${ }^{84}$ Traditional risk assessment of chemical substances uses the ratio between predicted environmental concentration versus a predicted no effect concentration (PEC/PNEC), an approach that has been applied to microplastics exposure scenarios, ${ }^{85}$ finding that $0.17 \%$ of global ocean surface waters are at risk, and increasing to $1.62 \%$ by the end of the century. Additionally, the limitations inherent to commonly used sampling methods (i.e., focusing on larger sized-microparticles), together with technical limitations in detecting 
smaller, nanoscale particles, are likely leading to an underestimation of the concentrations of both micro- and nanoplastics in the environment, ${ }^{86}$ indicating that exposures and therefore risks are likely larger. Furthermore, the seafloor and sediments are thought to be the ultimate sink for plastics, ${ }^{87,88}$ through uptake in marine ecosystems ${ }^{8990}$ and changes in particle density and sinking rates due to biofouling, ${ }^{91-93}$ so these niches and the organisms inhabiting them are predicted to suffer higher exposures. Quantifying these environmental concentrations, exposure routes and ecological fates (including additional niches) requires more data, and will be important for assessing exposure scenarios driving disturbances to biosphere integrity. Several different approaches could be applied to deal with data gaps. A toxicity-based threshold would be set at PEC/PNEC = 1, with NE-PB exceedances already evident in several regions. However, additional deliberations would be necessary for considering changes in distribution of species or sensitivities, moving beyond toxicity to biodiversity and functionality.

\section{DISCUSSION AND CONCLUSIONS}

Choice of Control Variable. The character of the NE-PB differs from the other PBs since there is no prehuman background level or baseline of NEs (with few exceptions, like metals). The NE-PB is also distinct because of the number and diversity of NEs, the likelihood that these will increase in future, and the diverse impacts that they may cause. Thus, there is a need for control variables that are constructed differently compared to those for other PBs. As discussed above, operational control variables are necessary in order to inform action and gauge progress.

We have presented a set of control variables that captures several of the complexities and characteristics of the NE-PB, ranging in feasibility, relevance and comprehensiveness. All have their strengths and weaknesses; none of them fulfill all the criteria on their own. We conclude that the nature of the planetary boundary for novel entities demands several different control variables, and that jointly, our set of control variables form the basis of a feasible strategy to alert planetary risks and inform action.

Are We Transgressing the Planetary Boundary for Novel Entities? A consistent trend-captured by our control variables is an increase over time in the production, diversity and global release of NEs. Despite major efforts in recent decades, safety assessment and subsequent regulations of chemical substances and other NEs, and the capacity of many countries to conduct these assessments and to enforce regulatory compliance, are not keeping up with the speed of introduction of new NEs. An ever-growing number of NEs are found in remote locations of the planet and the number of grossly contaminated locations is increasing despite remediation efforts. In addition, many distinct and partly interacting (e.g., synergistic) effects of NEs on Earth's physical and ecological systems are being reported. In short, rapid growth in diversity and production volumes and releases outstrips society's ability to assess, let alone manage NEs. Planetary burdens are already considerable. ${ }^{1}$ Large differences in management capacity between countries of different income levels means that even when chemicals and waste management is improved in some jurisdictions, NEs will continue to be produced, used and disposed of with insufficient or nonexistent regulations and enforcement elsewhere, and thus NEs continue to be emitted into the environment. ${ }^{94}$ This is a global concern, thus, there is a need for integrated and just cross-border solutions to address the problem with emissions of novel entities, such as plastic pollution. ${ }^{95}$

We have adopted a weight-of-evidence approach to answer the question of whether we are transgressing the safe operating space of the NE-PB based on the set of control variables. Compelled by the increasing temporal trends seen in most of the control variables, we answer the question by comparing the rate of change in the amount of chemicals, including plastics, that are produced and released to the environment, relative to our capacity to conduct safety assessments and monitoring. We submit that the safe operating space of the NE-PB is exceeded when annual production and releases increase at a pace that outstrips the global capacity for assessment and monitoring.

Based on the evidence presented here, we submit that we are now in a zone of exceedance of the Planetary Boundary for novel entities. Further, even if we were to stabilize or reduce production and releases, the effects due to our transgression of the NE-PB will still be a threat due to the persistence of many novel entities. Thus, we conclude that increases in production and releases of novel entities are not consistent with keeping humanity within the safe operating space, in the light of the global capacity for management.

We invite the research community to continue work, using the impact pathway and understanding of the NE-PB presented here, to develop more operational control variables, more robust quantification of the NE-PB, and better-defined limits for NE emissions. However, these continued research efforts need to go in parallel with urgent action to manage today's NE-PB threats. Global data with improved spatiotemporal granularity can be gathered, but this activity should not delay immediate action, aiming to prevent harm earlier in the impact pathway, before the stage of Earth system effects. Measures to reduce releases and emissions of NEs to the environment are essential, including a higher degree of circularity in product supply chains, material and product design, design for recycling, and safe and sustainable chemicals. $^{96,97}$ We must also address the issue of inequitable resource distribution and affluence that drives resource use and emissions $^{98}$ and hampers their effective regulation.

Just as actions aimed at curbing climate change transitioned from concentration or discharge-based limits to fixed caps on greenhouse gas emissions, ${ }^{99}$ calls for caps on plastic production and use have been made. ${ }^{7}$ We suggest that the same approach is needed for all NEs, getting back within the safe operating space can only be achieved through globally capping emissions of NEs at a rate that is commensurate with the physical and chemical capacity of the Earth system.

If we are to mitigate current damage and avoid future surprises from unknown NE-PB threats, a more preventive and precautionary hazard-based approach is needed to address novel entities. We are not naive to the considerable challenge posed by reducing chemical and plastic releases in order to respect the NE-PB, especially with lock-in of chemical supply providing resistance against such changes. The recent call for an international science-policy body with oversight over chemicals and waste ${ }^{100}$ may provide a forum for informing such actions that are needed to help safeguard the Earth system. 


\section{ASSOCIATED CONTENT}

\section{SI Supporting Information}

The Supporting Information is available free of charge at https://pubs.acs.org/doi/10.1021/acs.est.1c04158.

Figures illustrating global production capacity of seven chemicals (Figures S1-S7), global production of pesticide active ingredients (Figure S8), plastics (Figure S9), and antibiotics (Figure S10), plus references (PDF)

\section{AUTHOR INFORMATION}

\section{Corresponding Authors}

Linn Persson - Stockholm Environment Institute, 10451

Stockholm, Sweden; Present Address: Swedish Society for Nature Conservation, SSNC, Box 4625, 11691

Stockholm, and Affiliated Researcher at Stockholm

Environment Institute, Sweden; 이이이.org/0000-0002-

7110-7089; Phone: +46-707176630;

Email: linn.persson@ssnc.se

Cynthia A. de Wit - Department of Environmental Science, Stockholm University, 10691 Stockholm, Sweden; (1) orcid.org/0000-0001-8497-2699;

Email: Cynthia.deWit@aces.su.se

\section{Authors}

Bethanie M. Carney Almroth - Department of Biology and Environmental Sciences, University of Gothenburg, 40530 Gothenburg, Sweden; (1) orcid.org/0000-0002-5037-4612

Christopher D. Collins - Department of Geography and Environmental Sciences, University of Reading, Reading, Berkshire RG6 6AH, United Kingdom; orcid.org/00000002-8282-2803

Sarah Cornell - Stockholm Resilience Centre, Stockholm University, 10691 Stockholm, Sweden; 이이.org/00000003-4367-1296

Miriam L. Diamond - Department of Earth Sciences; and School of the Environment, University of Toronto, Toronto, Canada M5S 3B1; (1) orcid.org/0000-0001-6296-6431

Peter Fantke - Quantitative Sustainability Assessment, Department of Technology, Management and Economics, Technical University of Denmark, 2800 Kgs. Lyngby, Denmark; (1) orcid.org/0000-0001-7148-6982

Martin Hassellöv - Department of Marine Sciences, University of Gothenburg, 40530 Gothenburg, Sweden

Matthew MacLeod - Department of Environmental Science, Stockholm University, 10691 Stockholm, Sweden; (1) orcid.org/0000-0003-2562-7339

Morten W. Ryberg - Quantitative Sustainability Assessment, Department of Technology, Management and Economics, Technical University of Denmark, 2800 Kgs. Lyngby, Denmark; (1) orcid.org/0000-0003-2589-8729

Peter Søgaard Jørgensen - Stockholm Resilience Centre, Stockholm University, 10691 Stockholm, Sweden; Global Economic Dynamics and the Biosphere, Royal Swedish Academy of Sciences, 10405 Stockholm, Sweden

Patricia Villarrubia-Gómez - Stockholm Resilience Centre, Stockholm University, 10691 Stockholm, Sweden

Zhanyun Wang - Institute of Environmental Engineering, ETH Zürich, 8093 Zürich, Switzerland; (1) orcid.org/00000001-9914-7659

Michael Zwicky Hauschild - Quantitative Sustainability Assessment, Department of Technology, Management and
Economics, Technical University of Denmark, $2800 \mathrm{Kgs.}$ Lyngby, Denmark

Complete contact information is available at: https://pubs.acs.org/10.1021/acs.est.1c04158

\section{Notes}

The authors declare no competing financial interest.

\section{ACKNOWLEDGMENTS}

This work was initiated with a workshop convened as part of Earth Resilience in the Anthropocene, an Advanced Investigator project funded by the European Research Council (grant ERC2016-ADG-743080). We thank Frida Åberg for excellent facilitation and technical and research support. The valuable input from all workshop delegates and the help of Jonathan Blumenthal from University of Toronto for producing Figure ${ }^{2}$ and the SI Figures are gratefully acknowledged.

\section{REFERENCES}

(1) UN Environment. Global Chemicals Outlook II - From Legacies to Innovative Solutions: Implementing the 2030 Agenda for Sustainable Development; 978-92-807-3745-5, 2019; p 700.

(2) Rockström, J.; Steffen, W.; Noone, K.; Persson, Å.; Chapin, F. S. I.; Lambin, E.; Lenton, T. M.; Scheffer, M.; Folke, C.; Schellnhuber, H. J.; Nykvist, B.; de Wit, C. A.; Hughes, T.; van der Leeuw, S.; Rodhe, H.; Sorlin, S.; Snyder, P. K.; Costanza, R.; Svedin, U.; Falkenmark, M.; Karlberg, L.; Corell, R. W.; Fabry, V. J.; Hansen, J.; Walker, B.; Liverman, D.; Richardson, K.; Crutzen, P.; Foley, J. Planetary Boundaries: Exploring the Safe Operating Space for Humanity. Ecol. Soc. 2009, 14 (2), No. 32.

(3) Steffen, W.; Richardson, K.; Rockstrom, J.; Cornell, S. E.; Fetzer, I.; Bennett, E. M.; Biggs, R.; Carpenter, S. R.; de Vries, W.; de Wit, C. A.; Folke, C.; Gerten, D.; Heinke, J.; Mace, G. M.; Persson, L. M.; Ramanathan, V.; Reyers, B.; Sorlin, S. Planetary Boundaries: Guiding Human Development on a Changing Planet. Science 2015, 347 (6223), 1259855-1259855.

(4) Diamond, M. L.; de Wit, C. A.; Molander, S.; Scheringer, M.; Backhaus, T.; Lohmann, R.; Arvidsson, R.; Bergman, A.; Hauschild, M.; Holoubek, I.; Persson, L.; Suzuki, N.; Vighi, M.; Zetzsch, C. Exploring the Planetary Boundary for Chemical Pollution. Environ. Int. 2015, 78, 8-15.

(5) Persson, L. M.; Breitholtz, M.; Cousins, I. T.; de Wit, C. A.; MacLeod, M.; McLachlan, M. S. Confronting Unknown Planetary Boundary Threats from Chemical Pollution. Environ. Sci. Technol. 2013, 47 (22), 12619-12622.

(6) Villarrubia-Gómez, P.; Cornell, S. E.; Fabres, J. Marine Plastic Pollution as a Planetary Boundary Threat - The Drifting Piece in the Sustainability Puzzle. Mar. Policy 2018, 96, 213-220.

(7) Lau, W. W. Y.; Shiran, Y.; Bailey, R. M.; Cook, E.; Stuchtey, M. R.; Koskella, J.; Velis, C. A.; Godfrey, L.; Boucher, J.; Murphy, M. B.; Thompson, R. C.; Jankowska, E.; Castillo Castillo, A.; Pilditch, T. D.; Dixon, B.; Koerselman, L.; Kosior, E.; Favoino, E.; Gutberlet, J.; Baulch, S.; Atreya, M. E.; Fischer, D.; He, K. K.; Petit, M. M.; Sumaila, U. R.; Neil, E.; Bernhofen, M. V.; Lawrence, K.; Palardy, J. E. Evaluating Scenarios toward Zero Plastic Pollution. Science 2020, 369 (6510), 1455-1461.

(8) Beaumont, N. J.; Aanesen, M.; Austen, M. C.; Börger, T.; Clark, J. R.; Cole, M.; Hooper, T.; Lindeque, P. K.; Pascoe, C.; Wyles, K. J. Global Ecological, Social and Economic Impacts of Marine Plastic. Mar. Pollut. Bull. 2019, 142, 189-195.

(9) Landrigan, P. J.; Fuller, R.; Acosta, N. J. R.; Adeyi, O.; Arnold, R.; Basu, N.; Baldé, A. B.; Bertollini, R.; Bose-O’Reilly, S.; Boufford, J. I.; Breysse, P. N.; Chiles, T.; Mahidol, C.; Coll-Seck, A. M.; Cropper, M. L.; Fobil, J.; Fuster, V.; Greenstone, M.; Haines, A.; Hanrahan, D.; Hunter, D.; Khare, M.; Krupnick, A.; Lanphear, B.; Lohani, B.; Martin, K.; Mathiasen, K. V.; McTeer, M. A.; Murray, C. J. L.; Ndahimananjara, J. D.; Perera, F.; Potočnik, J.; Preker, A. S.; Ramesh, 
J.; Rockström, J.; Salinas, C.; Samson, L. D.; Sandilya, K.; Sly, P. D.; Smith, K. R.; Steiner, A.; Stewart, R. B.; Suk, W. A.; van Schayck, O. C. P.; Yadama, G. N.; Yumkella, K.; Zhong, M. The Lancet Commission on Pollution and Health. Lancet 2018, 391 (10119), $462-512$.

(10) Diamond, M. L. Toxic Chemicals as Enablers and Poisoners of the Technosphere. Anthr. Rev. 2017, 4 (2), 72-80.

(11) Grandjean, P.; Bellanger, M. Calculation of the Disease Burden Associated with Environmental Chemical Exposures: Application of Toxicological Information in Health Economic Estimation. Environ. Health 2017, 16 (1), 123.

(12) SAICM. SAICM Intersessional Process - Virtual Working Groups 2020-2021. Http://Www.Saicm.Org/Beyond2020/ IntersessionalProcess/VirtualWorkingGroups/Tabid/8563/ Language/En-US/Default.Aspx (accessed 2021/1/25).

(13) MacLeod, M.; Breitholtz, M.; Cousins, I. T.; Wit, C. A.; de Persson, L. M.; Rudén, C.; McLachlan, M. S. Identifying Chemicals That Are Planetary Boundary Threats. Environ. Sci. Technol. 2014, 48 (19), 11057-11063.

(14) Arp, H. P. H.; Kühnel, D.; Rummel, C.; MacLeod, M.; Potthoff, A.; Reichelt, S.; Rojo-Nieto, E.; Schmitt-Jansen, M.; Sonnenberg, J.; Toorman, E.; Jahnke, A. Weathering Plastics as a Planetary Boundary Threat: Exposure, Fate, and Hazards. Environ. Sci. Technol. 2021, 22 (11), 7246-7255.

(15) Hochella, M. F.; Mogk, D. W.; Ranville, J.; Allen, I. C.; Luther, G. W.; Marr, L. C.; McGrail, B. P.; Murayama, M.; Qafoku, N. P.; Rosso, K. M.; Sahai, N.; Schroeder, P. A.; Vikesland, P.; Westerhoff, P.; Yang, Y. Natural, Incidental, and Engineered Nanomaterials and Their Impacts on the Earth System. Science 2019, 363 (6434), eaau8299.

(16) Sala, S.; Saouter, E. Planetary Boundaries and Chemical Pollution: A Grail Quest? Chem. Int. 2014, 36 (6), 2.

(17) Bernhardt, E. S.; Rosi, E. J.; Gessner, M. O. Synthetic Chemicals as Agents of Global Change. Front. Ecol. Environ. 2017, 15 (2), 84-90.

(18) Perlinger, J. A.; Gorman, H. S.; Norman, E. S.; Obrist, D.; Selin, N. E.; Urban, N. R.; Wu, S. Measurement and Modeling of Atmosphere-Surface Exchangeable Pollutants (ASEPs) To Better Understand Their Environmental Cycling and Planetary Boundaries. Environ. Sci. Technol. 2016, 50 (17), 8932-8934.

(19) Jahnke, A.; Arp, H. P. H.; Escher, B. I.; Gewert, B.; Gorokhova, E.; Kühnel, D.; Ogonowski, M.; Potthoff, A.; Rummel, C.; SchmittJansen, M.; Toorman, E.; MacLeod, M. Reducing Uncertainty and Confronting Ignorance about the Possible Impacts of Weathering Plastic in the Marine Environment. Environ. Sci. Technol. Lett. 2017, 4 (3), 85-90.

(20) Napper, I. E.; Thompson, R. C. Environmental Deterioration of Biodegradable, Oxo-Biodegradable, Compostable, and Conventional Plastic Carrier Bags in the Sea, Soil, and Open-Air Over a 3-Year Period. Environ. Sci. Technol. 2019, 53 (9), 4775-4783.

(21) Chiba, S.; Saito, H.; Fletcher, R.; Yogi, T.; Kayo, M.; Miyagi, S.; Ogido, M.; Fujikura, K. Human Footprint in the Abyss: 30 Year Records of Deep-Sea Plastic Debris. Mar. Policy 2018, 96, 204-212.

(22) Royer, S.-J.; Ferrón, S.; Wilson, S. T.; Karl, D. M. Production of Methane and Ethylene from Plastic in the Environment. PLoS One 2018, 13 (8), e0200574.

(23) Shen, M.; Huang, W.; Chen, M.; Song, B.; Zeng, G.; Zhang, Y. (Micro)Plastic Crisis: Un-Ignorable Contribution to Global Greenhouse Gas Emissions and Climate Change. J. Cleaner Prod. 2020, 254, 120138.

(24) Zheng, J.; Suh, S. Strategies to Reduce the Global Carbon Footprint of Plastics. Nat. Clim. Change 2019, 9 (5), 374-378.

(25) GESAMP. Sources, Fate and Effects of Microplastics in the Marine Environment: Part 2 of a Global Assessment. IMO/FAO/UNESCOIOC/UNIDO/WMO/IAEA/UN/ UNEP/UNDP Joint Group of Experts on the Scientific Aspects of Marine Environmental Protection. Rep. Stud. GESAMP No. 93., 2016.
(26) Maxwell, S. L.; Fuller, R. A.; Brooks, T. M.; Watson, J. E. M. Biodiversity: The Ravages of Guns, Nets and Bulldozers. Nature 2016, 536 (7615), 143-145.

(27) Sala, S.; Goralczyk, M. Chemical Footprint: A Methodological Framework for Bridging Life Cycle Assessment and Planetary Boundaries for Chemical Pollution: Chemical Footprint Methodology for Aquatic Ecosystems. Integr. Environ. Assess. Manage. 2013, 9 (4), 623-632.

(28) Posthuma, L.; Bjørn, A.; Zijp, M. C.; Birkved, M.; Diamond, M. L.; Hauschild, M. Z.; Huijbregts, M. A. J.; Mulder, C.; Van de Meent, D. Chemical Footprints: Thin Boundaries Support Environmental Quality Management. Environ. Sci. Technol. 2014, 48 (22), 1302513026.

(29) Bjørn, A.; Diamond, M.; Birkved, M.; Hauschild, M. Z. Chemical Footprint Method for Improved Communication of Freshwater Ecotoxicity Impacts in the Context of Ecological Limits. Environ. Sci. Technol. 2014, 48 (22), 13253-13262.

(30) Reppas-Chrysovitsinos, E.; Sobek, A.; MacLeod, M. ScreeningLevel Exposure-Based Prioritization to Identify Potential POPs, VPvBs and Planetary Boundary Threats among Arctic Contaminants. Emerg. Contam. 2017, 3 (2), 85-94.

(31) Sobek, A.; Bejgarn, S.; Rudén, C.; Breitholtz, M. The Dilemma in Prioritizing Chemicals for Environmental Analysis: Known versus Unknown Hazards. Env. Sci. Process. Impacts 2016, 18, 1042.

(32) Rial, J. A.; Pielke Sr, R. A.; Beniston, M.; Claussen, M.; Canadell, J.; Cox, P.; Held, H.; de Noblet-Ducoudré, N.; Prinn, R.; Reynolds, J. F.; Salas, J. D. Nonlinearities, Feedbacks and Critical Thresholds within the Earth's Climate System. Clim. Change 2004, 65 (1/2), 11-38.

(33) Scheffer, M.; Carpenter, S.; Foley, J. A.; Folke, C.; Walker, B. Catastrophic Shifts in Ecosystems. Nature 2001, 413 (6856), 591596.

(34) EEA. Chemicals for a Sustainable Future: Report of the EEA Scientific Committee Seminar: Copenhagen, 17 May 2017; European Environment Agency.; Publications Office: LU, 2018.

(35) Wang, Z.; Walker, G. W.; Muir, D. C. G.; Nagatani-Yoshida, K. Toward a Global Understanding of Chemical Pollution: A First Comprehensive Analysis of National and Regional Chemical Inventories. Environ. Sci. Technol. 2020, 54 (5), 2575-2584.

(36) Levi, P. G.; Cullen, J. M. Mapping Global Flows of Chemicals: From Fossil Fuel Feedstocks to Chemical Products. Environ. Sci. Technol. 2018, 52 (4), 1725-1734.

(37) Geyer, R.; Jambeck, J. R.; Law, K. L. Production, Use, and Fate of All Plastics Ever Made. Sci. Adv. 2017, 3 (7), e1700782.

(38) Søgaard Jørgensen, P.; Folke, C.; Henriksson, P. J. G.; Malmros, K.; Troell, M.; Zorzet, A. Coevolutionary Governance of Antibiotic and Pesticide Resistance. Trends Ecol. Evol. 2020, 35 (6), 484-494.

(39) Unruh, G. C. Understanding Carbon Lock-In. Energy Policy 2000, 28 (12), 817-830.

(40) Beddoe, R.; Costanza, R.; Farley, J.; Garza, E.; Kent, J.; Kubiszewski, I.; Martinez, L.; McCowen, T.; Murphy, K.; Myers, N.; Ogden, Z.; Stapleton, K.; Woodward, J. Overcoming Systemic Roadblocks to Sustainability: The Evolutionary Redesign of Worldviews, Institutions, and Technologies. Proc. Natl. Acad. Sci. U. S. A. 2009, 106 (8), 2483-2489.

(41) Alaee, M. An Overview of Commercially Used Brominated Flame Retardants, Their Applications, Their Use Patterns in Different Countries/Regions and Possible Modes of Release. Environ. Int. 2003, 29 (6), 683-689.

(42) Kristiansson, E.; Coria, J.; Gunnarsson, L.; Gustavsson, M. Does the Scientific Knowledge Reflect the Chemical Diversity of Environmental Pollution? - A Twenty-Year Perspective. Environ. Sci. Policy 2021, 126, 90-98.

(43) CEFIC. Fact and Figures of the European Chemical Industry 2018. CEFIC. 2018.

(44) Rochman, C. M.; Hoh, E.; Kurobe, T.; Teh, S. J. Ingested Plastic Transfers Hazardous Chemicals to Fish and Induces Hepatic Stress. Sci. Rep. 2013, 3 (1), 3263. 
(45) Geyer, R. Production, Use, and Fate of Synthetic Polymers. In Plastic Waste and Recycling; Elsevier, 2020; pp 13-32. DOI: 10.1016/ B978-0-12-817880-5.00002-5.

(46) Ryberg, M. W.; Hauschild, M. Z.; Wang, F.; Averous-Monnery, S.; Laurent, A. Global Environmental Losses of Plastics across Their Value Chains. Resour. Conserv. Recycl. 2019, 151, 104459.

(47) Borrelle, S. B.; Ringma, J.; Law, K. L.; Monnahan, C. C.; Lebreton, L.; McGivern, A.; Murphy, E.; Jambeck, J.; Leonard, G. H.; Hilleary, M. A.; Eriksen, M.; Possingham, H. P.; De Frond, H.; Gerber, L. R.; Polidoro, B.; Tahir, A.; Bernard, M.; Mallos, N.; Barnes, M.; Rochman, C. M. Predicted Growth in Plastic Waste Exceeds Efforts to Mitigate Plastic Pollution. Science 2020, 369 (6510), 15151518

(48) Hopewell, J.; Dvorak, R.; Kosior, E. Plastics Recycling: Challenges and Opportunities. Philos. Trans. R. Soc., B 2009, 364 (1526), 2115-2126.

(49) Nielsen, T. D.; Hasselbalch, J.; Holmberg, K.; Stripple, J. Politics and the Plastic Crisis: A Review throughout the Plastic Life Cycle. Wiley Interdiscip. Rev.: Energy Environ. 2020, 9 (1). DOI: $10.1002 /$ wene. 360 .

(50) Lebreton, L.; Andrady, A. Future Scenarios of Global Plastic Waste Generation and Disposal. Palgrave Commun. 2019, 5 (1), 6.

(51) Cousins, I. T.; Ng, C. A.; Wang, Z.; Scheringer, M. Why Is High Persistence Alone a Major Cause of Concern? Environ. Sci. Process. Impacts 2019, 21 (5), 781-792.

(52) Fenner, K.; Scheringer, M. The Need for Chemical Simplification As a Logical Consequence of Ever-Increasing Chemical Pollution. Environ. Sci. Technol. 2021, 55, acs.est.1c04903.

(53) Stieger, G.; Scheringer, M.; Ng, C. A.; Hungerbühler, K. Assessing the Persistence, Bioaccumulation Potential and Toxicity of Brominated Flame Retardants: Data Availability and Quality for 36 Alternative Brominated Flame Retardants. Chemosphere 2014, 116, $118-123$.

(54) CEFIC. The European Chemical Industry - a Vital Part of Europe's Future, Facts and Figures 2021; The European Chemical Industry Council, CEFIC, 2021.

(55) ECHA. Universe of Registered Substances. European Chemicals Agency, ECHA. Https://Echa.Europa.Eu/Fr/Universe-of-RegisteredSubstances (accessed 2021/5/25).

(56) Sha, B.; Johansson, J. H.; Benskin, J. P.; Cousins, I. T.; Salter, M. E. Influence of Water Concentrations of Perfluoroalkyl Acids (PFAAs) on Their Size-Resolved Enrichment in Nascent Sea Spray Aerosols. Environ. Sci. Technol. 2021, 55, acs.est.0c03804.

(57) Johansson, J. H.; Salter, M. E.; Acosta Navarro, J. C.; Leck, C.; Nilsson, E. D.; Cousins, I. T. Global Transport of Perfluoroalkyl Acids via Sea Spray Aerosol. Environ. Sci. Process. Impacts 2019, 21 (4), 635-649.

(58) Vaida, V. Ocean Sea Spray, Clouds, and Climate. ACS Cent. Sci. 2015, 1 (3), 112-114.

(59) Jørgensen, P. S.; Aktipis, A.; Brown, Z.; Carrière, Y.; Downes, S.; Dunn, R. R.; Epstein, G.; Frisvold, G. B.; Hawthorne, D.; Gröhn, Y. T.; Gujar, G. T.; Jasovský, D.; Klein, E. Y.; Klein, F.; Lhermie, G.; Mota-Sanchez, D.; Omoto, C.; Schlüter, M.; Scott, H. M.; Wernli, D.; Carroll, S. P.; Living with Resistance project. Antibiotic and Pesticide Susceptibility and the Anthropocene Operating Space. Nat. Sustainable 2018, 1 (11), 632-641.

(60) Sühring, R.; Diamond, M. L.; Bernstein, S.; Adams, J. K.; Schuster, J. K.; Fernie, K.; Elliott, K.; Stern, G.; Jantunen, L. M. Organophosphate Esters in the Canadian Arctic Ocean. Environ. Sci. Technol. 2021, 55 (1), 304-312.

(61) Peng, X.; Chen, M.; Chen, S.; Dasgupta, S.; Xu, H.; Ta, K.; Du, M.; Li, J.; Guo, Z.; Bai, S. Microplastics Contaminate the Deepest Part of the World's Ocean. Geochem. Perspect. Lett. 2018, 1-5.

(62) Napper, I. E.; Davies, B. F. R.; Clifford, H.; Elvin, S.; Koldewey, H. J.; Mayewski, P. A.; Miner, K. R.; Potocki, M.; Elmore, A. C.; Gajurel, A. P.; Thompson, R. C. Reaching New Heights in Plastic Pollution-Preliminary Findings of Microplastics on Mount Everest. One Earth 2020, 3 (5), 621-630.
(63) EEA. The European Environment: State and Outlook 2020 : Knowledge for Transition to a Sustainable Europe; European Environment Agency; Publications Office: LU, 2019.

(64) UNECE. About PRTR. Https://Prtr.Unece.Org/about-PRTR (accessed 2021/11/13).

(65) Galarneau, E.; Makar, P. A.; Sassi, M.; Diamond, M. L. Estimation of Atmospheric Emissions of Six Semivolatile Polycyclic Aromatic Hydrocarbons in Southern Canada and the United States by Use of an Emissions Processing System. Environ. Sci. Technol. 2007, 41 (12), 4205-4213.

(66) EC. European Commission, European Pollutant Release and Transfer Register, EPRTR. Https://Ec.Europa.Eu/Environment/ Industry/Stationary/e-Prtr/Legislation.Htm (accessed 2021/5/4).

(67) Oberschelp, C.; Pfister, S.; Raptis, C. E.; Hellweg, S. Global Emission Hotspots of Coal Power Generation. Nat. Sustain. 2019, 2 (2), 113-121.

(68) Jambeck, J. R.; Geyer, R.; Wilcox, C.; Siegler, T. R.; Perryman, M.; Andrady, A.; Narayan, R.; Law, K. L. Plastic Waste Inputs from Land into the Ocean. Science 2015, 347 (6223), 768-771.

(69) Karlsson, T. M.; Arneborg, L.; Broström, G.; Almroth, B. C.; Gipperth, L.; Hassellöv, M. The Unaccountability Case of Plastic Pellet Pollution. Mar. Pollut. Bull. 2018, 129 (1), 52-60.

(70) Fendall, L. S.; Sewell, M. A. Contributing to Marine Pollution by Washing Your Face: Microplastics in Facial Cleansers. Mar. Pollut. Bull. 2009, 58 (8), 1225-1228.

(71) OSPAR Commission. OSPAR Background Document on PreProduction Plastic Pellets. https://www.ospar.org/documents?v= 39764 (accessed 2021-11-13).

(72) European Commission. Directorate General for Research and Innovation. A Circular Economy for Plastics: Insights from Research and Innovation to Inform Policy and Funding Decisions; Publications Office: LU, 2019.

(73) Posthuma, L.; van Gils, J.; Zijp, M. C.; van de Meent, D.; de Zwart, D. Species Sensitivity Distributions for Use in Environmental Protection, Assessment, and Management of Aquatic Ecosystems for 12386 Chemicals. Environ. Toxicol. Chem. 2019, 38 (4), 905-917.

(74) Walters, D. M.; Jardine, T. D.; Cade, B. S.; Kidd, K. A.; Muir, D. C. G.; Leipzig-Scott, P. Trophic Magnification of Organic Chemicals: A Global Synthesis. Environ. Sci. Technol. 2016, 50 (9), 4650-4658.

(75) Escher, B. I.; Stapleton, H. M.; Schymanski, E. L. Tracking Complex Mixtures of Chemicals in Our Changing Environment. Science 2020, 367 (6476), 388-392.

(76) Aurisano, N.; Albizzati, P. F.; Hauschild, M.; Fantke, P. Extrapolation Factors for Characterizing Freshwater Ecotoxicity Effects. Environ. Toxicol. Chem. 2019, 38 (11), 2568-2582.

(77) Kounina, A.; Margni, M.; Shaked, S.; Bulle, C.; Jolliet, O. Spatial Analysis of Toxic Emissions in LCA: A Sub-Continental Nested USEtox Model with Freshwater Archetypes. Environ. Int. 2014, 69, 67-89.

(78) Rochman, C. M.; Browne, M. A.; Underwood, A. J.; van Franeker, J. A.; Thompson, R. C.; Amaral-Zettler, L. A. The Ecological Impacts of Marine Debris: Unraveling the Demonstrated Evidence from What Is Perceived. Ecology 2016, 97 (2), 302-312.

(79) Bucci, K.; Tulio, M.; Rochman, C. M. What Is Known and Unknown about the Effects of Plastic Pollution: A Meta-analysis and Systematic Review. Ecol. Appl. 2020, 30 (2). DOI: 10.1002/eap.2044. (80) Salerno, M.; Berlino, M.; Mangano, M. C.; Sarà, G. Microplastics and the Functional Traits of Fishes: A Global Metaanalysis. Glob. Change Biol. 2021, 27 (12), 2645-2655.

(81) Arias-Andres, M.; Rojas-Jimenez, K.; Grossart, H.-P. Collateral Effects of Microplastic Pollution on Aquatic Microorganisms: An Ecological Perspective. TrAC, Trends Anal. Chem. 2019, 112, 234240.

(82) Seeley, M. E.; Song, B.; Passie, R.; Hale, R. C. Microplastics Affect Sedimentary Microbial Communities and Nitrogen Cycling. Nat. Commun. 2020, 11 (1), 2372.

(83) Phuong, N. N.; Zalouk-Vergnoux, A.; Poirier, L.; Kamari, A.; Châtel, A.; Mouneyrac, C.; Lagarde, F. Is There Any Consistency 
between the Microplastics Found in the Field and Those Used in Laboratory Experiments? Environ. Pollut. 2016, 211, 111-123.

(84) Koelmans, A. A.; Redondo-Hasselerharm, P. E.; Mohamed Nor, N. H.; Kooi, M. Solving the Nonalignment of Methods and Approaches Used in Microplastic Research to Consistently Characterize Risk. Environ. Sci. Technol. 2020, 54 (19), 12307-12315.

(85) Everaert, G.; De Rijcke, M.; Lonneville, B.; Janssen, C. R.; Backhaus, T.; Mees, J.; van Sebille, E.; Koelmans, A. A.; Catarino, A. I.; Vandegehuchte, M. B. Risks of Floating Microplastic in the Global Ocean. Environ. Pollut. 2020, 267, 115499.

(86) Lindeque, P. K.; Cole, M.; Coppock, R. L.; Lewis, C. N.; Miller, R. Z.; Watts, A. J. R.; Wilson-McNeal, A.; Wright, S. L.; Galloway, T. $S$. Are We Underestimating Microplastic Abundance in the Marine Environment? A Comparison of Microplastic Capture with Nets of Different Mesh-Size. Environ. Pollut. 2020, 265, 114721.

(87) Peng, G.; Bellerby, R.; Zhang, F.; Sun, X.; Li, D. The Ocean's Ultimate Trashcan: Hadal Trenches as Major Depositories for Plastic Pollution. Water Res. 2020, 168, 115121.

(88) Kane, I. A.; Clare, M. A.; Miramontes, E.; Wogelius, R.; Rothwell, J. J.; Garreau, P.; Pohl, F. Seafloor Microplastic Hotspots Controlled by Deep-Sea Circulation. Science 2020, 368 (6495), $1140-1145$

(89) Choy, C. A.; Robison, B. H.; Gagne, T. O.; Erwin, B.; Firl, E.; Halden, R. U.; Hamilton, J. A.; Katija, K.; Lisin, S. E.; Rolsky, C.; S. Van Houtan, K. The Vertical Distribution and Biological Transport of Marine Microplastics across the Epipelagic and Mesopelagic Water Column. Sci. Rep. 2019, 9 (1), 7843.

(90) Kane, I. A.; Clare, M. A. Dispersion, Accumulation, and the Ultimate Fate of Microplastics in Deep-Marine Environments: A Review and Future Directions. Front. Earth Sci. 2019, 7, 80.

(91) Fazey, F. M. C.; Ryan, P. G. Biofouling on Buoyant Marine Plastics: An Experimental Study into the Effect of Size on Surface Longevity. Environ. Pollut. 2016, 210, 354-360.

(92) Ryan, P. G. How Quickly Do Albatrosses and Petrels Digest Plastic Particles? Environ. Pollut. 2015, 207, 438-440.

(93) Holmström, A. Plastic Films on the Bottom of the Skagerack. Nature 1975, 255 (5510), 622-623.

(94) Zhang, Q.; Jiang, X.; Tong, D.; Davis, S. J.; Zhao, H.; Geng, G.; Feng, T.; Zheng, B.; Lu, Z.; Streets, D. G.; Ni, R.; Brauer, M.; van Donkelaar, A.; Martin, R. V.; Huo, H.; Liu, Z.; Pan, D.; Kan, H.; Yan, Y.; Lin, J.; He, K.; Guan, D. Transboundary Health Impacts of Transported Global Air Pollution and International Trade. Nature 2017, 543 (7647), 705-709.

(95) Borrelle, S. B.; Rochman, C. M.; Liboiron, M.; Bond, A. L.; Lusher, A.; Bradshaw, H.; Provencher, J. F. Opinion: Why We Need an International Agreement on Marine Plastic Pollution. Proc. Natl. Acad. Sci. U. S. A. 2017, 114 (38), 9994-9997.

(96) Wang, Z.; Hellweg, S. First Steps Toward Sustainable Circular Uses of Chemicals: Advancing the Assessment and Management Paradigm. ACS Sustainable Chem. Eng. 2021, 9 (20), 6939-6951.

(97) Aurisano, N.; Weber, R.; Fantke, P. Enabling a Circular Economy for Chemicals in Plastics. Curr. Opin. Green Sustain. Chem. 2021, 31, 100513.

(98) Wiedmann, T.; Lenzen, M.; Keyßer, L. T.; Steinberger, J. K. Scientists' Warning on Affluence. Nat. Commun. 2020, 11 (1), 3107.

(99) Asheim, G. B.; Fæhn, T.; Nyborg, K.; Greaker, M.; Hagem, C.; Harstad, B.; Hoel, M. O.; Lund, D.; Rosendahl, K. E. The Case for a Supply-Side Climate Treaty. Science 2019, 365 (6451), 325-327.

(100) Wang, Z.; Altenburger, R.; Backhaus, T.; Covaci, A.; Diamond, M. L.; Grimalt, J. O.; Lohmann, R.; Schäffer, A.; Scheringer, M.; Selin, H.; Soehl, A.; Suzuki, N. We Need a Global Science-Policy Body on Chemicals and Waste. Science 2021, 371 (6531), 774-776. 